\title{
MASYARAKAT HUKUM ADAT DATUK SINARO PUTIH: PASANG SURUT KEKUASAAN ADAT DI TENGAH HEGEMONI NEGARA
}

\author{
Ridwan, Isman \\ Universitas Muaro Bungo \\ e-mail: iwan09ukm@gmail.com
}

\begin{abstract}
The Bungo District Government issued Local Regulation Number 9 of 2007 concerning the mention of the Village Head to Rio, the Village Becomes a Hamlet and Hamlet Becomes a Village which raises fundamental problems faced by the Indigenous Government of Datuk Sinaro Putih. The problem is the existence of dualism at the level of village institutions, which is caused by the Role of Rio (Village Chief) who is so free to regulate all customary issues in the customary law community Datuk Sinaro Putih which has been regulated by Customary Institutions led by Customary Stakeholders. The method used is descriptive qualitative method. The existence of the Customary Law Society Datuk Sinaro Putih still exists officially recognized by Perda No. 6 of 2006 concerning Customary Law Society Datuk Sinaro Putih. They still have customary forests as their ancestral heritage. The Hamlet Government has replaced the power of Datuk Sinaro Putih in the field of general government. But customary power is still held by Datuk Sinaro Putih, including control of customary forest areas. The descendants of Datuk Sinaro Putih made an effort to maintain their existence, including designing Village Regulations on the Customary Law Society of Datuk Sinaro Putih and holding regular adat vows and staging traditional arts in the traditional unit of Datuk Sinaro Putih. This article has never been published in any journal and in any form.
\end{abstract}

Keywords: customary law community, Datuk Sinaro Putih, customary power, state hegemony

\section{Abstrak}

Pemerintah Kabupaten Bungo mengeluarkan Perda Nomor 9 tahun 2007 tentang Penyebutan Kepala Desa Menjadi Rio, Desa Menjadi Dusun dan Dusun Menjadi Kampung yang menimbulkan masalah mendasar yang dihadapi oleh Pemerintahan Adat Datuk Sinaro Putih. Permasalahannya yaitu adanya dualisme di tingkat kelembagaan desa, yang diakibatkan Peran Rio (Kepala Desa) yang begitu leluasa untuk mengatur segala permasalahan adat pada masyarakat hukum adat Datuk Sinaro Putih yang selama ini diatur oleh Lembaga Adat yang dipimpin oleh Pemangku Adat. Metode yang digunakan adalah metode kualitatif deskriptif. Eksistensi Masyarakat Hukum Adat Datuk Sinaro Putih masih ada yang diakui secara resmi oleh Perda No. 6 Tahun 2006 tentang Masyarakat Hukum Adat Datuk Sinaro Putih. Mereka masih mempunyai hutan adat sebagai warisan nenek moyang mereka. Pemerintahan Dusun telah menggantikan kekuasaan Datuk Sinaro Putih di bidang pemerintahan umum. Namun kekuasaan adat masih dipegang oleh Datuk Sinaro Putih, termasuk penguasaan terhadap wilayah hutan adat. Anak keturunan Datuk Sinaro Putih melakukan upaya untuk mempertahankan eksistensinya diantaranya merancang Peraturan Desa tentang Masyarakat Hukum Adat Datuk Sinaro Putih dan mengadakan secara berkala kaul adat dan pementasan seni tardisional dalam wilayah kesatuan adat Datuk Sinaro Putih. Artikel ini belum pernah dimuat di jurnal manapun dan dalam bentuk apapun.

Kata Kunci : masyarakat hukum adat, datuk sinaro putih, kekuasaan adat, hegemoni Negara 


\section{PENDAHULUAN}

Era otonomi daerah merupakan babak baru bagi pemerintah daerah di seluruh Indonesia untuk berkarya dan berkreasi untuk kemajuan daerahnya masing-masing. Dalam menyambut otonomi daerah tersebut beberapa daerah di Indonesia membangkitkan lagi sistem pemerintahan tradisional yang dulu pernah eksis di wilayah mereka. Pemerintahan tradisional itu seperti pemerintahan Nagari di Sumatera Barat, Gampong di Aceh dan Desa di Jawa dan Marga di Sumatera Selatan.

Untuk menghormati kekhasan budaya lokal dalam otonomi daerah maka Pemerintah Daerah Kab. Bungo, Jambi mengeluarkan Peraturan Daerah Kabupaten Bungo Nomor 3 tahun 2006 tentang Masyarakat Hukum Adat Datuk Sinaro Putih. Masyarakat Hukum Adat Datuk Sinaro Putih merupakan masyarakat tradisional yang masih terkait dalam bentuk paguyuban (rehtsgemeenschap), ada kelembagaan adat, ada wilayah hukum, ada pranata dan perangkat hukum adat yang masih ditaati, serta masih mengadakan pemungutan hasil hutan diwilayah hutan sekitarnya.

Namun setahun setelahnya yakni pada tahun 2007 pemerintah daerah Bungo memberlakukan pula Perda baru yaitu Peraturan Daerah Kabupaten Bungo Nomor 9 tahun 2007 tentang Penyebutan Kepala Desa Menjadi Rio, Desa Menjadi Dusun dan Dusun Menjadi Kampung. Peraturan Daerah tersebut menjadikan dusun sebagai pemerintahan terendah di Kabupaten Bungo ${ }^{2}$. Perda tersebut bertujuan untuk mengembalikan nilai-nilai sejarah yang pernah ada di Kabupaten Bungo dengan menunjukkan karakteristik daerah terutama dari segi adat dan budaya yang telah ada pada sistem Pemerintahan Dusun dahulunya. Namun Perda No. 9 tersebut tidak mengecualikan Masyarakat Hukum Adat Datuk Sinaro Putih yang mempunyai karakeristik yang khas berbeda dari pemerintahan dusun. Pemerintahan Adat Datuk Sinaro Putih sebelumnya juga telah diberi wewenang oleh Pemda Bungo untuk mengatur urusannya sendiri melalui Perda No. 3 Tahun 2006.

Dengan diberlakukannya Peraturan Daerah Kabupaten Bungo Nomor 9 tahun 2007 tentang Penyebutan Kepala Desa Menjadi Rio, Desa Menjadi Dusun dan Dusun Menjadi Kampung tersebut telah menimbulkan beberapa masalah mendasar yang dihadapi oleh Pemerintahan Adat Datuk Sinaro Putih Baru Daerah terebut selama ini tetap setia menjaga nilai-nilai lokal dan melestarikan Masyarakat Hukum Adat Datuk Sinaro Putih. Permasalahan tersebut bertitik tolak dari adanya dualisme di tingkat kelembagaan desa, hal ini diakibatkan Peran Rio (Kepala Desa) yang begitu leluasa untuk mengatur segala permasalahan adat mereka.

Sejak zaman kolonial Datuk Sinaro Putih memiliki peran sentral dalam mengambil keputusan terhadap segala permasalahan di seluruh wilayah kekuasaannya. Baik kekuasaan dalam bidang pemerintahan, kekuasaan atas hutan dan sumber daya alam yang ada didalam wilayah pemerintahannya. Dengan diberlakukannya Peraturan Daerah Kabupaten Bungo Nomor 9 tahun 2007 tentang Penyebutan Kepala Desa Menjadi Rio, Desa Menjadi Dusun dan Dusun Menjadi Kampung maka kekuasaan tersebut semakin terpinggirkan. Hal inilah yang menarik penulis untuk melakukan kajian tentang eksistensi kekuasaan Masyarakat Hukum Adat Datuk Sinaro Putih.

\section{Masyarakat Hukum Adat}

Secara teoritis terbentuknya masyarakat hukum adat disebabkan karena adanya faktor ikatan yang mengikat masing-masing anggota masyarakat hukum adat tersebut.

Faktor ikatan yang membentuk masyarakat hukum adat secara teoritis adalah:

1. Faktor Genealogis (keturunan)

2. Faktor Teritorial (wilayah)

Berdasarkan kedua faktor ikatan diatas, kemudian terbentuklah masyarakat hukum adat, yang dalam studi hukum adat disebut tiga tipe utama persekutuan adat yaitu: 
1. Persekutuan Hukum Genealogis

2. Persekutuan Hukum Teritorial

3. ersekutuan hukum Hukum Genealogis-Teritorial, yang merupakan penggabungan dua persekutuan hukum diatas.

\section{Persekutuan Hukum Genealogis}

Pada persekutuan hukum (masyarakat hukum) geneologis dasar pengikatan utama anggota kelompok adalah persamaan dalam keturunan, artinya anggota-anggota kelompok itu terikat karena merasa berasal dari nenek moyang yang sama. Menurut para ahli hukum adat dimasa Hindia Belanda masyarakat hukum genealogis ini dapat dibedakan dalam tiga macam yaitu yang bersifat patrilineal, matrilinial, dan bilateral atau parental.

a) Masyarakat yang patrilineal

Pada masyarakat yang patrilineal ini susunan masyarakatnya ditarik menurut garis keturunan dari bapak (garis laki-laki). Kata ini seringkali disamakan dengan patriarkat atau patriarki, meskipun pada dasarnya artinya berbeda. Patrilineal berasal dari dua kata, yaitu pater (bahasa Latin) yang berarti "ayah", dan linea (bahasa Latin) yang berarti "garis". Jadi, "patrilineal" berarti mengikuti "garis keturunan yang ditarik dari pihak ayah".

Sementara itu patriarkat berasal dari dua kata yang lain, yaitu pater yang berarti "ayah" dan archein (bahasa Yunani) yang berarti "memerintah". Jadi, "patriarki" berarti "kekuasaan berada di tangan ayah atau pihak laki-laki".

b) Masyarakat Matrelineal

Pada masyarakat yang patrilineal ini susunan masyarakatnya ditarik menurut garis keturunan dari ibu (garis perempuan). Kata ini seringkali disamakan dengan matriarkhat atau matriarkhi, meskipun pada dasarnya artinya berbeda. Matrilineal berasal dari dua kata, yaitu mater (bahasa Latin) yang berarti "ibu", dan linea (bahasa Latin) yang berarti "garis". Jadi, "matrilineal" berarti mengikuti "garis keturunan yang ditarik dari pihak ibu".

Sementara itu matriarkhat berasal dari dua kata yang lain, yaitu mater yang berarti "ibu" dan archein (bahasa Yunani) yang berarti "memerintah". Jadi, "matriarkhi" berarti "kekuasaan berada di tangan ibu atau pihak perempuan".

c) Masyarakat yang bilateral atau parental

Pada masyarakat yang bilateral atau parental, susunan masyarakatnya ditarik dari garis keturunan orang tuanya yaitu bapak dan ibu bersama-sama sekaligus.

\section{Persekutuan Hukum Teritorial}

Mengenai persekutuan hukum teritorial, dasar pengikatan utama anggota kelompoknya adalah daerah kelahiran dan menjalani hidup bersama ditempat yang sama. Menurut R. van Dijk (1954) persekutuan hukum teritorial ini dibedakan kedalam tiga macam yaitu: ${ }^{5}$

1) Persekutuan Desa (dorp)

2) Persekutuan Daerah (streek)

3) Perserikatan dari beberapa Desa.

Termasuk dalam persekutuan desa adalah seperti, desa orang jawa, yang merupakan satu tempat kediaman bersama di dalam daerahnya sendiri termasuk beberapa pedukuhan yang terletak di sekitarnya yang tunduk pada perangkat desa yang berkediaman di pusat desa. Kemudian yang termasuk persekutuan daerah adalah seperti kesatuan masyarakat "nagari" di Minangkabau, "marga" di Sumatera Selatan dan Lampung, "negorij" di Minahasa, dan Maluku, di masa lampau yang merupakan suatu daerah kediamanbersama dan menguasai tanah hak ulayat bersama yang terdiri dari beberapa dusun atau kampong dengan satu pusat pemerintahan bersama. Sedangkan yang termasuk perserikatan desa adalah 
apabila di antara beberapa desa atau marga yang terletak berdampingan yang masing-masing berdiri sendiri mengadakan perjanjian kerja sama untuk mengatur kepentingan bersama, misalnya kepentingan dalam mengatur pemerintahan adat bersama, pertahanan bersama, kehidupan ekonomi, pertanian dan pemasaran bersama.

\section{Persekutuan Hukum Genealogis-Teritorial}

Berikutnya mengenai persekutuan hukum genealogis-teritorial dasar pengikatan utama pengikat utama anggota kelompoknya adalah dasar persekutuan hukum genealogis dan teritorial. Jadi pada persekutuan hukum ini, para anggotanya bukan saja terkait pada tempat kediaman daerah tertentu tetapi juga terikat pada hubungan keturunan dalam ikatan pertalian daerah dan atau kekerabatan. Kita dapat membedakan masyarakat genealogis-teritorial dalam bentuk yang asli (yang tradisional) adalah seperti, "Kuria" dengan "Huta-huta"-nya dilingkungan masyarakat Tapanuli (Angkola, Mandailing), "Marga" dengan "Dusundusun" di Sumatera Selatan, "Marga" dengan "Tiyuh-tiyuh" di Lampung, dalam bentuk yang lama, dimana para anggota kesatuan masyarakat itu terikat pada suatu daerah Kuria/Marga dan terikat pula pada suatu marga Keturunan (Batak) atau "Buway" di Lampung. Di dalam bentuknya yang baru (yang campuran antarsuku) adalah seperti masyarakat yang mendiami suatu daerah kecamatan atau pedesaan di Lampung setelah masuknya transmigran, terutama setelah kemerdekaan Republik Indonesia, di mana tidak saja terdapat pedesaan atau pedukuhan orang Jawa, Sunda, Bali yang sifatnya teritorial. Sedangkan di pasar Kecamatan atau pada pasar Desa bermukim penduduk campuran yang bermacam-macam asal suku dan masyarakat adatnya. Dengan demikian di dalam suatu daerah di mana terdapat masyarakat yangteritorial genealogis, akan berlaku dualisme atau pluralisme hukum yaitu hukum administrasi pemerintahan berdasarkan perundang-undangan, hukum adat (yang baru) yang berlaku bagi anggota kesatuan masyarakat desa yang bersangkutan, dan hukum adat yang tradisional bagi kesatuan-kesatuan masyarakat hukum tertentu menurut daerah asalnya masing-masing dan tentu saja berlaku pula hukum antar adat yang berbeda dalam pergaulan masyarakat campuran.

\section{Masyarakat Hukum Adat Datuk Sinaro Putih}

Masyarakat Hukum Adat Datuk Sinaro Putih adalah masyarakat tradisional yang masih terkait dalam bentuk paguyuban (rehtsgemeenschap), ada kelembagaan adat, ada wilayah hukum, ada pranata dan perangkat hukum adat yang masih ditaati, masih mengadakan pemungutan hasil hutan diwilayah hutan sekitarnya ${ }^{6}$. Adapun wilayah Masyarakat Hukum Adat Datuk Sinaro Putih meliputi Dusun Baru Pelepat, Dusun Batu Kerbau dan Dusun Lubuk Telau Kecamatan Pelepat Kabupaten Bungo yang berwenang untuk mengatur dan mengurus kepentingan masyarakat setempat, berdasarkan asal-usul dan adat istiadat setempat yang diakui dan dihormati dalam sistem Pemerintahan Negara Kesatuan Republik Indonesia.

Datuk Sinaro Putih adalah Nenek Moyang Masyarakat Hukum Adat Dusun Baru Pelepat, Dusun Batu Kerbau dan Dusun Lubuk Telau yang berasal dari Daerah Minang Kabau yang sampai saat ini keturunannya masih diakui sebagai pimpinan adat di Dusun Baru Pelepat, Dusun Batu Kerbau dan Dusun Lubuk Telau. Datuk Sinaro Putih mempunyai pembantu yakni Datuk Rangkayo Mulio yang merupakan nenek Moyang Masyarakat Dusun Baru Pelepat dan Dusun Lubuk Telau yang diberikan kewenangan untuk menjadi pimpinan Masyarakat Hukum Adat Datuk Sinaro Putih dalam wilayah Dusun Baru Pelepat dan Dusun Lubuk Telau. Datuk Rangkayo Mulio berkedudukan di Dusun Baru Pelepat, kekuasaanya diwariskan secara turun temurun sampai generasi saat ini. Tiang Panjang adalah nenek moyang masyarakat Dusun Batu Kerbau yang diberi kewenangan oleh Datuk Sinaro putih untuk memegang kekuasaan sebagai pimpinan adat yang diwariskan secara turun temurun sampai generasi saat ini. 
Selain itu adapula beberapa kelembagaan lain dibawah kekuasaan Datuk Sinaro Putih diantara yang disebut dengan Tuo Negeri yakni perangkat kelembagaan masyarakat hukum adat yang bertugas menyelesaikan masalah-masalah ditingkat masyarakat. Kemudian kelembagaan lain yang disebut Lep yang merupakan majelis yang dibentuk dari dan oleh peserta musyawarah untuk mengambil keputusan dalam sidang atau musyawarah adat yang sifatnya tidak tetap. Kelembagaan lainnya adalah Pegawai Syara' yakni perangkat kelembagaan adat yang bertugas melaksanakan syari'at Islam dalam Kesatuan Adat Datuk Sinaro Putih.

Kelembagaan adat yang secara turun temurun bertugas di bidang kesehatan dan bencana dalam wilayah Masyarakat Hukum Adat Datuk Sinaro Putih disebut dengan Dukun Tengganai. Sutan Marajo lelo dan sultan Marajo indo adalah perangkat kelembagaan adat yang mempunyai kekuasaan ditingkat dusun dan bertanggung jawab kepada datuk mangkayo mulio. Datuk rabun dan penghulu Alam adalah perangkat kelembagaan adat yang bertugas membantu pelaksanaan tugas datuk tiang panjang ditingkat dusun dalam wilayah Desa Batu Kerbau. Dubalang adalah perangkat kelembagaan adat yang mengurusi hal-hal yang berkaitan dengan masalah keamanan masyarakat hukum adat. Monti Rajo adalah perangkat kelembagaan adat yang bertugas membantu melakukan komunikasi dan menyampaikan informasi kepada masyarakat. Jonang adalah perangkat kelembagaan adat yang bertugas untuk melakukan pelayanan dalam acara-acara adat. Terakhir Bundo Kanduang adalah kelembagaan adat yang merupakan representasi kaum perempuan dalam masyarakat hukum adat. Malokok adalah prosesi adat untuk menerima masyarakat yang berasal dari luar masyarakat hukum adat datuk sinaro putih.

\section{Pemerintahan Dusun (Desa)}

Desa yang di sebut dengan nama lain yang selanjutnya di sebut Desa adalah kesatuan masyarakat hukum yang memiliki batas-batas wilayah yang berwenang untuk mengatur dan mengurus kepentingan masyarakat setempat, berdasarkan asal-usul dan adat istiadat setempat di akui dan di hormati dalam Sistem Pemerintahan Negara kesatuan Republik Indonesia. ${ }^{7}$ Pemerintahan desa adalah penyelenggaraan pemerintahan oleh pemerintah desa dan Badan Permusyawaratan Desa (BPD) dalam mengatur dan mengurus kepentingan masyarakat setempat berdasarkan asal-usul dan adat istiadat setempat yang diakui dan dihormati dalam sistem Pemerintahan Negara Kesatuan republik Indonesia.

Pengaturan tentang desa dalam Udang-Undang Nomor 32 Tahun 2004 Tentang Otonomi Daerah tersebut diharapkan Pemerintah Desa bersama masyarakat secara bersama-sama menciptakan kemandirian desa. Kemandirian tersebut dapat dilihat dari kewenangan yang diberikan yang tertuang dalam pasal 206, yang menyebutkan bahwa desa merupakan kesatuan masyarakat hukum yang memiliki kewenangan untuk mengatur dan mengurus kepentingan masyarakat setempat. Kewenangan Desa mencakup: keberadaan lembaga perwakilan desa atau badan Perwakilan Desa (BPD) sebagai bentuk miniatur DPRD di tingkat Kota maupun Kabupaten. Kewenangan ini berdampak pada mekanisme penyelenggaraan pemerintah desa yang selama ini tidak memiliki "lawan" atau yang mengontrol jalannya Pemerintahan desa.

\section{Rio}

Rio merupakan penyebutan Kepala Pemerintah Dusun di Kabupaten Bungo, hal ini sesuai dengan ketentuan dalam Pasal 2 Peraturan Daerah Kabupaten Bungo Nomor 9 tahun 2007 Tentang Penyebutan Kepala Desa Menjadi Rio, Desa Menjadi Dusun dan Dusun menjadi Kampung. Sama halnya seperti Kepala Desa, Rio merupakan penyelenggara pemerintahan bersama Badan Permusyawaratan Dusun (BPD) dalam mengatur dan mengurus kepentingan masyarakat berdasarkan asal-usul dan adat istiadat setempat yang diakui dan dihormati dalam sistem Pemerintahan Negara Kesatuan republik Indonesia Gelar Rio selaku pemangku adat diberikan oleh Lembaga Adat Dusun dengan berpedoman kepada ketentuan adat yang sudah berlaku di dusun setempat yang ditetapkan. Berdasarkan Peraturan Daerah 
No. 9 Tahun 2007 tersebut, pemberian gelar adat dilakukan pada acara pelantikan Rio. Rio dipilih langsung oleh masyarakat dan dilantik oleh Bupati atau pejabat yang ditunjuk dihadapan masyarakat Dusun setempat dengan pengucapan janji sesuai dengan ketentuan berlaku.

\section{METODE}

Penelitian ini menggunakan metode penelitian kualitatif-deskriptif. Bogdan dan Taylor mendefinisikan metodologi kualitatif sebagai prosedur penelitian yang menghasilkan data deskriptif berupa kata-kata tertulis atau lisan dari orang-orang dan perilaku yang dapat diambil. ${ }^{10}$ Dengan dasar tersebut, maka penelitian ini diharapkan mampu memberikan gambaran mengenai eksistensi kekuasaan Masyarakat Hukum Adat Datuk Sinaro Putih dengan didukung data-data tertulis maupun data-data hasil wawancara. Lokasi yang digunakan dalam penelitian ini adalah di Dusun Batu Kerbau, Dusun Baru Pelepat dan Dusun Lubuk Telau, Kecamatan Pelepat, Kabupaten Bungo. Ketiga dusun tersebut merupakan wilayah Masyarakat Hukum Adat Datuk Sinaro Putih dimana nilai-nilai adat istiadat serta kearifan tradisional hingga saat ini masih melekat kuat dalam aktivitas kehidupan sehari-hari. Ke tiga dusun tersebut merupakan pusat dari keberlangsungan adat istiadat Datuk Sinaro Putih. Waktu penelitian ini direncanakan selama satu tahun, yaitu dari bulan Juli 2018 sampai Juni 2019.

\section{HASIL DAN PEMBAHASAN}

\section{Eksistensi Masyarakat Hukum Adat Datuk Sinaro Putih.}

Eksistensi Masyarakat Hukum Adat Datuk Sinaro Putih masih ada. Karena mereka diakui secara resmi oleh Peraturan Daerah Kabupaten Bungo No. 6 Tahun 2006 tentang Masyarakat Hukum Adat Datuk Sinaro Putih. Mereka masih mempunyai hutan adat sebagai warisan nenek moyang Datuk Sinar Putih. Setelah dilakukan wawancara cukup mendalam ternyata kewenangan Masayarakat Hukum Adat Datuk Sinaro Putih telah dicampuri oleh Pemerintah Daerah misalnya saat Pemda Bungo mengizinkan perusahaan sawit PT. PML mengolah lahan hutan adat Datuk Sinaro Putih.

Walaupun eksistensi Masayarakat Hukum Adat Datuk Sinaro Putih masih diakui tetapi keberadaan mereka terus terancam karena kekuasaan mereka atas hutan adatnya tidak lagi penuh. Negara dengan mengatasnamakan untuk meningkatkan pendapatan daerah terus memberikan izin pada perusahaan perkebunan untuk mengolah sebagian lahan hutan adat Datuk Sinaro Putih menjadi kawasan perkebunan sawit. Akhirnya sungai mereka menjadi tercemar, setiap musim hujan tiba terjadi banjir. Beberapa keluarga yang tinggal di bantaran sungai terpaksa dialihkan ke kawasan yang lebih tinggi oleh pemerintah dusun karena terpapar dan menjadi korban banjir. Sementara itu pada musim kemarau mereka ditimpa kekeringan akibat hutan penahan air di hulu sungai sudah banyak yang gundul.

\section{Hubungan Pemerintah Dusun dengan Masyarakat Hukum Adat Datuk Sinaro Putih}

Pemerintahan Dusun telah menggantikan kekuasaan Datuk Sinaro Putih di bidang pemerintahan umum. Akan tetapi kekuasaan adat masih dipegang oleh Datuk Sinaro Putih, termasuk penguasaan terhadap wilayah hutan adat. Walaupun Datuk Rio (Kepala Desa) berperan sebagai pemangku adat berdasarkan Perda Kabupaten Bungo No. 9 Tahun 2009 tentang Penyebutan Kepada Desa Menjadi Rio, Desa menjadi Dusun dan Dusun Menjadi Kampung, tetapi ia masih dibawah payung panji Datuk Sinaro Putih dalam bidang adat. Keputusan-keputusan dalam bidang adat masih berada ditangan Datuk Sinaro Putih. 
Dilema atas hubungan pemerintah dusun dengan Datuk Sinaro utih masih sering terjadi terutama untuk kebijakan-kebijakan yang sifatnya formal. Kebijakan yang terkait dengan investasi perusahaan di wilayah Masyarakat Hukum Adat Datuk Sinaro Putih sering tidak mengakomodir aspirasi Datuk Sinaro Putih sendiri karena telah diputuskan oleh Pemda bersama Pemerintahan Dusun. Selain itu masuknya transmigrasi ke wilayah hutan adat Datuk Sinaro Putih tidak dapat mereka tolak karena sudah menjadi kebijakan pemerintah pusat dan daerah.

\section{Upaya anak keturunan Datuk Sinaro Putih untuk mempertahankan eksitensinya}

Anak keturunan Datuk Sinaro Putih telah melakukan berbagai upaya untuk mempertahankan eksistensinya diantaranya saat ini sedang merancang Peraturan Desa untuk melindungi Masyarakat Hukum Adat Datuk Sinaro Putih. Akan tetapi secara Adat kewenangan Datuk Sinaro Putih tidak dapat dihilangkan di daerah Dusun Batu Kerbau karena merupakan warisan adat turun temurun yang dihormati oleh masyarakat setempat Selain itu anak keturunan Datuk Sinaro Putih juga mengadakan acara tahunan dan lima tahunan dalam bentuk kaul adat dan pementasan seni tardisional dalam wilayah kesatuan adat Datuk Sinaro Putih, yakni antar dusun dan kampong di wilayah Datuk Sinaro Putih. Kemudian sampai saat ini Datuk Sinaro Putih juga masih belum memberikan izin pengolahan hutan adat yang masih tersisa kepada Perusahaan yang sudah mengajukan izin perkebunan ke Pemda Bungo. Selanjutnya mereka juga melobi Pemda agar menjadikan hutan adat sebagai hutan resapan air agar masyarakat terhindar dari banjir dan dusun Batu Kerbau dijadikan "Dusun Tangguh Bencana” oleh Pemda Bungo

\section{KESIMPULAN}

Berdasarkan pembahasan penelitian diatas maka dapat disimpulkan bahwa aksistensi Masyarakat Hukum Adat Datuk Sinaro Putih masih ada yang diakui oleh Perda Kab. Bungo No. 6 Tahun 2006 tentang Masyarakat Hukum Adat Datuk Sinaro Putih. Hubungannya dengan pemerintah dusun yakni kekuasaan dibidang pemerintahan umum dipegang oleh Datuk Rio sebagai Kepala Dusun sedangkan kekuasaan dibidang adat tetap dipegang oleh Datuk Sinaro Putih. Sedangkan upaya anak keturunan Datuk Sinaro Putih untuk mempertahan eksistensi Masyarakat Hukum Adat Datuk Sinaro Putih adalah dengan membuat peraturan desa tentang Masyarakat Hukum Adat Datuk Sinaro Putih, mengadakan acara tahunan dan lima tahunan dalam bentuk kaul adat dan pementasan seni tardisional dalam wilayah kesatuan adat Datuk Sinaro Putih, yakni antar dusun dan kampong di wilayah Datuk Sinaro Putih. Kemudian sampai saat ini Datuk Sinaro Putih juga masih belum memberikan izin pengolahan hutan adat yang masih tersisa kepada Perusahaan yang sudah mengajukan izin perkebunan ke Pemda Bungo. Selanjutnya mereka juga melobi Pemda agar menjadikan hutan adat sebagai hutan resapan air agar masyarakat terhindar dari banjir dan dusun Batu Kerbau dijadikan "Dusun Tangguh Bencana" oleh Pemda Bungo.

\section{KESIMPULAN}

1. Penelitian ini mesti dikembangkan lebih mendalam dan cakupan yang luas tentang masyarakat hukum adat Datuk sinaro Putih

2. Penelitian tentang masyarakat hukum adat disekitar masyarakat hukum adat Datuk Sinaro Putih perlu dilakukan untuk melihat bagaimana mereka mempertahankan kekuasaan adat mereka.

3. Pemda Kabupaten Bungo agar lebih sensitive terhadap hak-hak masyarakat hukum adat berdasarkan asal usulnya 


\section{DAFTAR PUSTAKA}

[1]. Astuti, W., \& Nurpeni, A. Policies for accelerating rural and agricultural development (study in Kampar Timur district, Kampar district, Riau Province).

[2]. Peraturan Daerah Kabupaten Bungo Nomor 3 tahun 2006 Tentang Masyarakat Hukum Adat Datuk Sinaro Putih

[3]. Peraturan Daerah Kabupaten Bungo Nomor 9 tahun 2007 tentang Penyebutan Kepala Desa Menjadi Rio, Desa Menjadi Dusun dan Dusun Menjadi Kampung

[4]. Wulansari, Dewi. C (2013). Hukum Adat Indonesia. Bandung: Repika Aditma

[5]. Peraturan Daerah Kabupaten Bungo Nomor 3 tahun 2006 Tentang Masyarakat Hukum Adat Datuk Sinaro Putih

[6]. Undang-Undang No. 32 Tahun 2004 tentang Otonomi Daerah

[7]. Solekhan, Moch. (2012). Penyelenggraan Pemerintahan Desa. Malang: Setara Press

[8]. Sondang P. Siagian. (2008). Kerangka Dasar Ilmu Administrasi. Jakarta: Rineka Cipta.

[9]. Peraturan Daerah Kabupaten Bungo Nomor 9 tahun 2007 Tentang Penyebutan Kepala Desa Menjadi Rio, Desa Menjadi Dusun dan Dusun menjadi Kampung. 